\title{
Income Inequality and Nutrition Insecurity among Rural Households: A Gini-Coefficient Causality Analysis in Ethiopia
}

\author{
Amare Tesfaw* \\ Department of Agricultural Economics: Debre Markos University, P. O.Box: 269 Debre Markos, Ethiopia \\ Sintayehu Musie \\ Department of Horticulture Debre Markos University, Debre Markos, Ethiopia \\ Esubalew Tadele \\ Department of Agricultural Economics: Debre Markos University, Debre Markos, Ethiopia \\ Solomon Ali \\ Department of Horticulture Debre Markos University, Debre Markos, Ethiopia
}

\begin{abstract}
Globally, malnutrition is an underlying cause for the deaths of more than 3.5 million children every year under the age of five and the prevalence of stunting, underweight and wasting among children in Ethiopia are 40\%, 25\%, and $9 \%$ respectively. More than $80 \%$ of the population in Northwestern Ethiopia resides in rural areas with highincome inequalities and consumption patterns. This contributed to dynamism in dietary diversity and subsequent nutrition insecurity among households. However, previous studies obscure in linking the extent of income inequality, its causes, and nutrition insecurity. We explored the extent of income inequality among rural households and its effect on nutrition security. Data were taken in 2017 from 378 households from different districts with varying crop production potentials. Multinomial Logistic Regression Model was employed to analyze the data. The result shows that the types of crops cultivated, total land size, and education level significantly $(\mathrm{P}<0.01)$ associated with households' dietary diversity. The Gini index was found to be 0.48 , depicting high-income inequality among the target households. Crop diversification together with on/off-farm activities can help narrow the existing income in inequality among rural households. Awareness and empowering women can help households increase their dietary diversity and improve nutrition security. Advocating home gardening can also enable households to focus on nutrient-rich diets. This will ultimately help create a well-nourished and healthy family.

Keywords: Food insecurity, Dietary diversity index, Nutrition insecurity, Gini Coefficient, Income inequality, Multinomial logit, Stunting
\end{abstract}

DOI: $10.7176 / \mathrm{JESD} / 11-17-01$

Publication date:September $30^{\text {th }} 2020$

\section{INTRODUCTION}

Globally, malnutrition is an underlying cause for the deaths of more than 3.5 million children under the age of 5 each year. Prevalence of stunting, underweight, and wasting among children in Ethiopia are 40\%, 25\% \& 9\%, respectively (EDHS, 2016). Ethiopia is being one of the underdeveloped countries in Africa, is suffering from such income variation. Such income disparity is an indicator of food and nutrition security.

East Gojjam is one of the Administrative Zones of the Amhara Region where more than $90 \%$ of its population is dwelling in rural area farming being the dominant economic activity. Rural households with farming sector dominant have faced with natural resource degradation and declining agricultural productivity in which it exposed them income dynamism among households and further, a cause to variation in wealth status and food availability has overall resulted in differences to nutritional insecurity for rural dwellers.

According to Rainer et al., (2000), food and nutrition security are achieved, if adequate food (quantity, quality, safety, socio-cultural acceptability) is always available and accessible for and satisfactorily used and utilized by all individuals to live a healthy and active life. Whereas dietary diversity is measured by adding the number of foods consumed (Ruel, 2002; Vakili et al., 2013). At the household level (Vakili et al., 2013) suggested that dietary diversity can be used as a proxy measure of food access while at the individual level as a reflection of dietary quality. The reference period usually ranges from one to three days, but seven days is also often used FAO, (2011) and periods of up to 15 days have been reported Drewnowski et al., (1997).

The anthropometric index height-for-age shows linear growth achievement in children. Shortness or stunting due to growth retardation indicates long-term, cumulative effects of inadequacies of nutrition and/or health. As a result, stunting is not only an indicator of poor nutritional status but also of unsatisfactory basic need coverage and therefore of absolute poverty. If a mother's nutrition and/or health situation are severely deteriorated, intrauterine growth retardation occurs and infants are born with low birth weight Rainer et al., (2000).

There exists a clear income variation among rural households. This income variability may be due to variation 
in productivity and the nature of the business a household is involved in. This contributes to dynamism in dietary diversity among rural households. However, the extent of income variation causes of income variability and the correlation between households' income and food/nutritional security has not been studied yet in East Gojjam.

The article dealt with examining the extent of income inequality and its linkage with nutrition security among rural households in East Gojjam, Northwestern Ethiopia. Thus, it was designed to achieve the objective of assessing the income disparity among rural households and its implications on food and nutritional security. The sequence of the next sections of the article is organized as follows: the upcoming section is regarding the overall research methodology and detail of methods followed along with the theoretical setup. The next part is the result and discussion, which is, augmented with empirical arguments and the final section is concluding remarks and future line of work as policy suggestions.

\section{METHODOLOGY}

\subsection{Description of the Study Area}

East Gojjam is one of the 11 Administrative Provinces of the Amhara National Regional State in Northwestern Ethiopia. Debre Markos, the capital city of the province, is situated $37^{\circ} 44^{\prime} 53$ "E longitude and $10^{\circ} 18^{\prime} 10^{\prime \prime} \mathrm{N}$ latitude. It is located $300 \mathrm{~km}$ Northwest of Addis Ababa.

East Gojjam has varying agro-ecologies that permit the cultivation of different crops. Districts situated at higher altitudes predominantly grow highland crops such as barley, potato, and faba bean. On the other hand, midaltitude $^{1}$ districts allow the growth of wheat, maize, and teff. Such agroecological variation limits crop diversity among districts.

\subsection{Data Types and Sources}

Both primary and secondary data sources were used for this study. Primary data were gathered from households, concerned government officials, and non-government bodies. Secondary data sources include data different from governmental offices and unpublished documents.

\subsection{Sample Size and Sampling Design}

The decisions involved in sampling procedures and the sample size to be taken are partly functions of the currently available information, time and other resources available, accessibility and openness of the target households

To generate primary data, the questionnaire was pre-tested on 24 households and then administered on 378 households that were selected following two stages. In the first stage, four districts (namely; Sinan, Gozamin, Basoliben, and Machakel) were selected purposively out of the 18 districts based on agricultural productivity potentials of rural households. In the second stage, considering the proportion of population respondents, different representative villages were selected randomly among each district and the household respondents were proportionately determined 378 sample size using sample size determination formula as suggested by Chochran, (1963).

$$
n=\frac{Z^{2} p q}{e^{2}}
$$

Where

$\mathrm{n}=$ Required sample size

$\mathrm{Z}=$ Inverse of the standard cumulative distribution that corresponds to the level of confidence

$e=$ Desired level of precision, $\mathrm{p}$ is the estimated proportion of an attribute that is present in the population and the value of $q=1-p$.

\subsection{Methods of Data collection}

Primary data were collected from target households using a questionnaire. To acquire supplementary information, checklists, and group discussions with community representatives were employed.

\subsection{Methods of Data Analysis}

Data obtained from the survey were analyzed using descriptive statistics, Gini Coefficient, and econometric analysis (Multinomial Logit Model).

\subsubsection{Descriptive Statistical Analysis}

For the description of the data; mean, percentage, variance, and standard deviation were used to examine households' socio-economic characteristics along with qualitative explanations for the appropriate interpretation of the analyzed data.

\footnotetext{
${ }^{1}$ Districts lying within altitude ranges between 1400 and 2800 meters above sea level, we literally categorized them as "mid-altitude" areas.
} 


\subsubsection{The Gini Coefficient Analysis}

There are several methods for estimating income inequality. The first method is to estimate the ratio of incomes obtained by, say, the bottom three percent of the population and the top ten percent of the population. Such an index shows the extent of inequality between the very rich and the very poor.

The other index which is frequently used to measure inequality is the Lorenz Curve' (named after the American Statistician C. Lorenz who invented it in 1905) which shows associations between percentages of income receivers and percentages of income. The value of the Gini Index, thus, used for an inequality measurement (Lambert, 1993). The vertical axis shows different percentages of income whereas the horizontal axis measures cumulative percentages of income receivers. The diagonal line OA in Figure 1 shows the line of exact equality because, at every point on it, the percentage of income receivers is equal to the percentage of income obtained.

The most favored index to measure inequality is the Gini Coefficient or G (called after Gini who invented it in 1912), which is the ratio of area $B$ to area $B+C$.

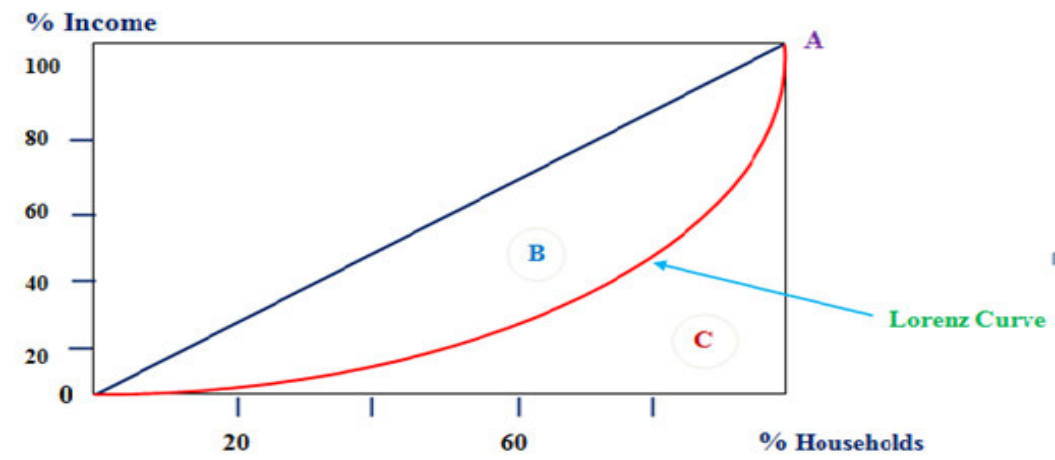

Figure 1. The Lorenz curve

The index is calculated as $G=\frac{B}{B+C}$.

The Gini Coefficient ranks according to the area between the Lorenz curve and the diagonal and it is a direct measure of income differences between every pair of incomes.

If the value of the Gini Coefficient:

$G=0$, everyone gets the same income (when the Lorenz curve overlaps with the line of equality)

$G=1$, only one person gets everything (area $\mathrm{C}$ becomes zero)

Clearly, for most countries the actual value of $\mathrm{G}$ lies between 0 and 1 .

According to Ruel, (2002), dietary diversity is the number of different foods or food groups consumed over a given reference period. To assess the households' meal, a 7 days' dietary recall was conducted to obtain information from respondents' food intake. Respondents were asked to recall all foods eaten and beverages taken in the previous twenty-four hours before the interview. Twelve food groups were used in assessing the dietary diversity of the respondents as summarized in Table 1. The dietary diversity scores for the respondents were therefore estimated using information collected from the 7 days' dietary recall FAO, (2007). A single point was awarded to each of the food groups consumed over the reference period giving a maximum sum of dietary diversity score of 12 points for each individual if his/her responses are positive to all food groups.

Table 1. Category of food items for diversity score

\begin{tabular}{ll|l}
\hline S.No & \multicolumn{1}{c|}{ Food Item Category } & \multicolumn{1}{c}{$\begin{array}{c}\text { Points } \\
(\text { Yes =1; No=0) }\end{array}$} \\
\hline 1. & Injera, bread, kollo and other related food items & \\
2. & Fruits & \\
3. & Vegetables; Root crops (potato, onion, carrot, etc.) & \\
4. & Meat and meat products & \\
5. & Vegetables & \\
6. & Butter, oil or fat consumed in any form & \\
7. & Legumes (beans, peas, chickpea, etc.) & \\
8. & Milk or milk products & \\
9. & Egg & \\
10. & Honey or sugar & \\
11. & Fish & \\
12. & Spices and condiments (tea, coffee, etc.) & \\
\hline
\end{tabular}

Source: Researchers, 2017. 
Table 2. Category of the dietary diversity score

\begin{tabular}{lccc} 
Category & Low & Medium & High \\
Dietary diversity score & $0-3$ & $4-6$ & $7-12$ \\
Sample of households & 116 & 128 & 134 \\
\hline
\end{tabular}

Source: Survey result, 2017

\subsubsection{Empirical Model}

The multinomial regression model is specified in the following manner (Greene,1993; Gujarat, 1992).

$$
\operatorname{Logit}\left(P_{i}\right)=\ln \left(P_{i} / 1-P_{i}\right)=\alpha+\beta_{1} X_{1}+\ldots+\beta_{n} X_{n}
$$

Where

$\ln \left(\mathrm{P}_{\mathrm{i}} / 1-\mathrm{P}_{\mathrm{i}}\right)=$ Dietary diversity category in logit model

$\mathrm{P}_{\mathrm{i}}=$ Medium Dietary Diversity

$1-\mathrm{P}_{\mathrm{i}}=$ Low or High Dietary Diversity

$\beta=$ coefficient

$\mathrm{X}=$ covariates

$\mathcal{E}=$ error term

\section{RESULTS AND DISCUSSION}

\subsection{Demographic Characteristics of Sample Households}

Demographic characteristics of households were considered to give briefs about the study population. As seen in Table 3, there is a significant $(\mathrm{P}<0.01)$ difference in age among districts. Age variation influences technology adoption and production potentials of households. Similarly, there is a significant $(\mathrm{P}<0.05)$ difference in family size among households.

Table 3. Demographic characteristics of sample households

\begin{tabular}{|c|c|c|c|c|c|c|c|}
\hline Districts & & Sinan & Gozamin & Basoliben & Machakel & Total & $\begin{array}{l}\mathbf{F}\left(\chi^{2}\right. \\
\text { Value })\end{array}$ \\
\hline Age & & $\begin{array}{l}39.33 \\
(9.14)\end{array}$ & $\begin{array}{l}39.40 \\
(10.50)\end{array}$ & $\begin{array}{l}42.35 \\
(9.75)\end{array}$ & $\begin{array}{l}47.09 \\
(9.76)\end{array}$ & $\begin{array}{l}43.21 \\
(10.01)\end{array}$ & $3.12 * * *$ \\
\hline Family size & & $\begin{array}{l}5.43 \\
(2.82)\end{array}$ & $\begin{array}{l}5.39 \\
(2.06)\end{array}$ & $\begin{array}{l}4.41 \\
(1.95)\end{array}$ & $\begin{array}{l}4.93 \\
(2.43)\end{array}$ & $\begin{array}{l}4.93 \\
(2.43)\end{array}$ & $4.24 * *$ \\
\hline $\operatorname{Sex}(\%)$ & $\begin{array}{l}\text { Male } \\
\text { Female }\end{array}$ & $\begin{array}{l}94.16 \\
4.94\end{array}$ & $\begin{array}{l}88.71 \\
11.29\end{array}$ & $\begin{array}{l}88.89 \\
11.11\end{array}$ & $\begin{array}{l}87.30 \\
12.70\end{array}$ & $\begin{array}{l}90.27 \\
10.51\end{array}$ & 6.15 \\
\hline
\end{tabular}

Source: Survey result, 2017.

Standard deviations in parentheses

$* * * \mathrm{p}<0.01, * * \mathrm{p}<0.05, * \mathrm{p}<0.1$

The sample households' age and family size statistics indicated that there was a significant $(\mathrm{P}<0.01)$ mean difference between households with high and low dietary diversity (Table 4). The variation in age between the two categories of households indicates that human productivity potential is highly age-dependent (the younger being more productive than the elderly). Family is the main source of labor for the farming community. The survey result indicated a significant difference in family size between the two groups of households.

Table 4.Age and family size between high and low diet consumers

\begin{tabular}{llll}
\hline Variables & High Dietary Diversity & Low Dietary Diversity & $\mathrm{t} / \chi^{2}$-Value \\
\hline \multirow{2}{*}{ Age } & 41.14 & 51.76 & $7.13^{* * *}$ \\
& $(9.60)$ & $(7.21)$ & \\
Family size & 5.40 & 2.19 & $39.00^{* * *}$ \\
Health Extension & $(2.30)$ & $(0.81)$ & $19.08^{* * *}$ \\
Frequency (\%) & 85.20 & 14.80 & 19 \\
\hline
\end{tabular}

Source: Survey result, 2017.

Standard deviations in parentheses

$* * * \mathrm{p}<0.01, * * \mathrm{p}<0.05, * \mathrm{p}<0.1$

Significant $(\mathrm{P}<0.01)$ differences between high and low dietary diversity consumers were observed in the frequency of extension service delivery which in turn resulted in dietary diversity. However, there was no significant educational background difference among districts or between these two groups of households' heads (Table 4).

There was no significant difference between groups because of the variation in the number of years of farming experience. This is because due to extensive health extension services, almost all households have more or less 
similar information regarding a healthy diet.

Table 5. Education levels of households among district

\begin{tabular}{lllllll}
\hline & & Sinan & Gozamin & Basoliben & Machakel & $\chi^{2}$ Value \\
\hline & Unable to read/write & 14.52 & 16.13 & 15.87 & 17.46 & \\
& Read and write & 27.42 & 32.26 & 26.98 & 33.33 & \\
Education Level (\%) & Grade 1-4 & 24.19 & 9.68 & 25.40 & 9.52 & 26.11 \\
& Grade 5-6 & 22.58 & 17.74 & 17.46 & 17.46 & \\
& Secondary school & 8.06 & 19.35 & 11.11 & 17.46 & \\
& Certificate and above & 3.23 & 4.84 & 3.17 & 4.76 & \\
\hline
\end{tabular}

Source: Survey result, 2017

\subsection{Socio-Economic Characteristics of Sample Households}

There is plot size variation among districts. Information obtained from key informants and field observation revealed that farmers who possess bigger plots use multiple cropping systems better than those who have relatively smaller plot sizes. This indicates that farmers who apply multiple cropping have better food diversity. The smaller the plot size a farmer owns, the greater will be the chance to cover that plot with mono-cropping.

\subsection{Lorenz Curve and the Gini Index}

To measure income distribution among households in varying agro-ecologies, the Lorenz curve and Gini index were used. Cumulative percentages of total income against income receivers were plotted beginning from the poorest households. Then, households were categorized into five (taking 20\%) and ranked based on income status (Table 2).

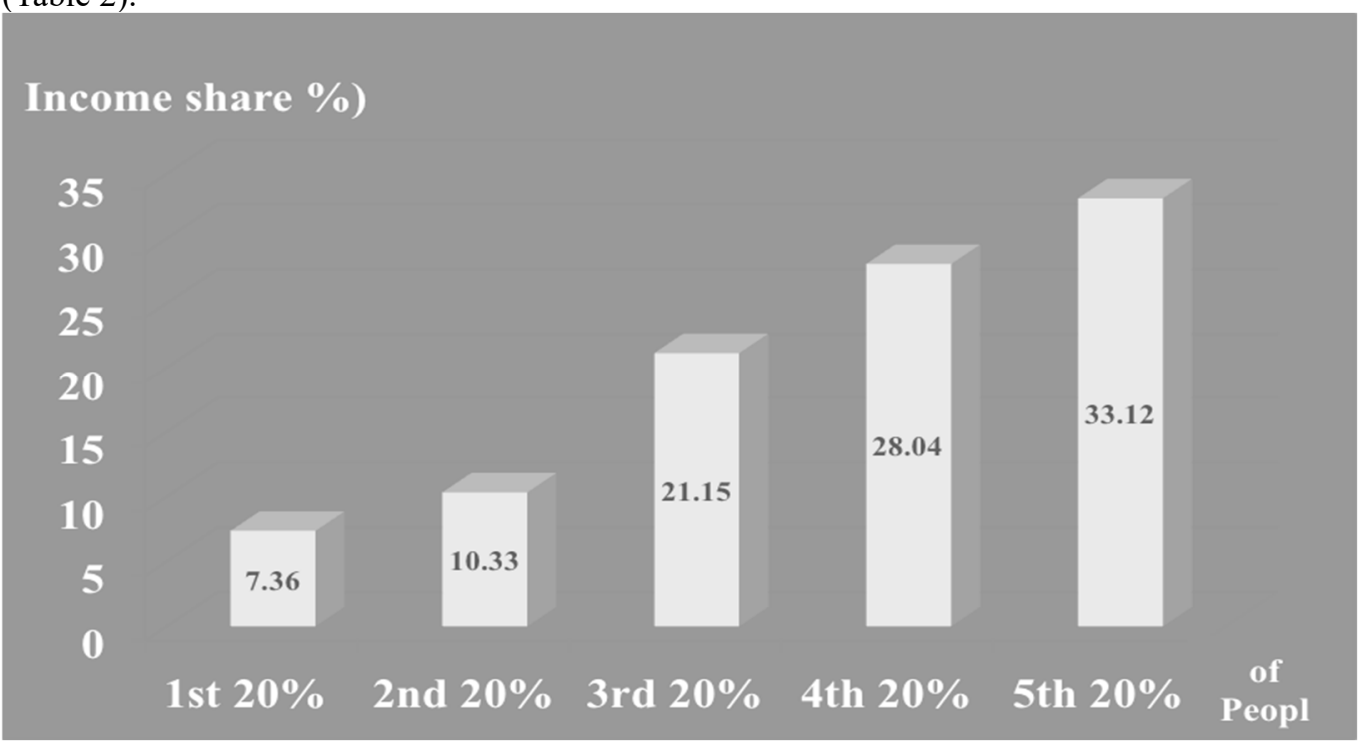

Figure 2. Income share held by 5 categories of income receivers

Source: Survey result, 2017.

The Gini index calculated (0.48) showed relatively severe income inequality, which is by far higher than the World Bank's, (2011) report for Ethiopia (0.33). The higher the variation, the lower the economic status of the society will be. As Galor and Moav (2004), higher inequality lowers growth by depriving the ability of lowerincome households to stay healthy and accumulate physical and human capital.

This variation in households' wealth status led to variation in household consumption and dietary diversity. The result showed significant differences in income between higher and lower diet consumer households. Diet and number of meal frequencies were negatively correlated. Dietary diversity was higher in low-income households than earn higher income receivers.

Significant differences were observed in the level of income between high and low diet consumer households. An odd fact in this study is that we found that households with higher income were found nutritionally less secure than low-income receivers households. This is because, low-income households usually purchase more diversified consumable food items as compared to households with better income who produce a large quantity of limited crops (mainly wheat and teff). Poor households purchase small but more diversified food items for household consumption.

The amount of income from livestock was quite different and significant between the two groups. On average this income was 7,466.15ETB for households with high dietary diversity and 10,660.81ETB for low dietary 
diversity.

Table 6 . Income for the high and low dietary diversity groups

\begin{tabular}{lccc}
\hline Variables & High dietary diversity & $\begin{array}{c}\text { Low dietary } \\
\text { diversity }\end{array}$ & t-Value \\
\hline Income from crop (ETB) & $16,791.55$ & $12,394.59$ & $2.07 * *$ \\
& $(6,813.01)$ & $(5,906.16)$ & $11.85^{* * *}$ \\
Income from livestock (ETB) & $7,466.15$ & $(19697.06)$ & $47.00^{* * *}$ \\
Off-farm income (ETB) & $(9,931.06)$ & $5,371.35$ & $(4,534.52)$ \\
\hline
\end{tabular}

Note: Figures in parentheses are standard deviations

$* * * \mathrm{p}<0.01, * * \mathrm{p}<0.05, * \mathrm{p}<0.1$.

The 2016 exchange rate of 1ETB is 21USD.

Source: Survey result, 2017.

\subsection{Dietary Diversity as Influenced by Various Factors \\ Plot size}

The survey result showed significant plot size variation between two groups of households. It was hypothesized that the larger the plot size allocated for farming, the larger will be the food diversity. Land size affected high dietary diversity positively and significantly $(\mathrm{P}<0.01)$. It implies that a unit increase in land size leads to an increase in dietary diversity by $1.23 \%$ on average. Similar findings were confirmed by Linderhof et al, (2016).

Key informants indicated that plot size dynamism between the two groups of households is the major cause of consuming the various diet. The larger the plot size that a household possesses, the greater will be the diversity (i.e., farmers will have better options to diversify crops on varying plots).

\section{Poultry}

Poultry owned positively and significantly affected high dietary diversity at $\mathrm{P}<0.01$ level of significance depicting that a unit increase in poultry will lead to an increase in dietary diversity by 2.351 .

\section{Farming experience (FARMEXP)}

Producer households with longer farming experience are supposed to positively influence dietary diversity. The result showed that older aged households were found to increase food diversity in a household. Farming experience positively and significantly $(\mathrm{P}<0.1)$ affected dietary diversity. A unit increase in the number of years of farming experience leads to dietary diversity approximately $3.10 \%$.

The longer higher the number years that a household head engages in farming, the better will be his knowledge about production systems as he acquires experiences of land use systems, land suitability, soil characteristics and the right types of agricultural inputs to be used on a particular field.

Table 7. The outcome of the Multivariate Logit Model

\begin{tabular}{lcccc}
\hline \multirow{2}{*}{ Variables } & \multicolumn{2}{c}{ High Dietary Diversity } & \multicolumn{2}{c}{ Low Dietary Diversity } \\
& Coefficient & P-Value & Coefficient & P-Value \\
\hline Plot size & 1.230 & $0.006^{* *}$ & 0.921 & $0.072^{*}$ \\
Poultry & 2.351 & $0.002^{* * *}$ & 1.032 & 0.536 \\
Farm income & 0.012 & 0.62 & 0.591 & 0.745 \\
Farm distance & -1.020 & $0.017^{* *}$ & -1.093 & $0.004^{* * *}$ \\
Age & -0.049 & 0.281 & -0.217 & 0.662 \\
Oxen & 0.336 & 0.114 & 0.178 & 0.124 \\
Sex & 1.091 & $0.048^{* *}$ & 0.919 & $0.012^{* *}$ \\
Education level & 0.481 & 0.231 & 0.238 & 0.066 \\
Health extension & 1.798 & $0.003^{* * *}$ & 2.131 & $0.007^{* * *}$ \\
Off-farm income & -0.125 & 0.543 & -0.712 & 0.228 \\
Access to irrigation & 1.293 & $0.002^{* * *}$ & 1.092 & $0.054^{* *}$ \\
\hline
\end{tabular}

Note: Standard deviations in parentheses. $* * * p<0.01, * * p<0.05, * p<0.1$. Number of observations $=180$; Category $=$ Medium dietary diversity. Chi-Square $=191.194^{* *} ;$ Pseudo $R^{2}=0.621$

Source: Survey result, 2017

\section{Access to irrigation}

Access to irrigation help farmers diversifies their production and diet. This shows that when the probability of households having access to irrigation water increases by 1, it leads to an increase in dietary diversity by 1.29 on 
average. A household with more diversified food items is better secured nutritionally. Muchenje and Mushunje (2013) found a positive contribution of access to irrigation in contributing to dietary diversity to rural households. Bouis (2007) concluded that access to home gardening influenced dietary diversity positively.

\section{Sex of household heads (SEX)}

Male-headed households were found to lower dietary diversity. The result indicated that sex negatively and significantly $(\mathrm{P}<0.05)$ influenced both high and low dietary diversity groups. The result indicated that female family heads either cultivate small but diversified crops in their plots. Muchenje and Mushunje (2013) observed a significant negative correlation between gender and dietary diversity.

\section{Frequency of health extension}

This variable positively and significantly $(\mathrm{P}<0.01)$ affected both high and low dietary diversity groups. A unit increment in the frequency of health extension contact increased dietary diversity by 1.80 on average for the high dietary diversity and 2.13 for the low dietary diversity groups. This is because, households with better health extension contacts are assumed to have good information about healthy nutrition.

\section{CONCLUSION AND RECOMMENDATIONS}

\subsection{Conclusion}

The Gini index indicated high-income inequality among rural households in the study area.

On the other hand, the level of income and nutrition security status of households were negatively correlated.

The real factors affecting households' dietary diversity like plot size, owning poultry, farm distance, sex, frequency of health extension service, and access to irrigation were identified. The result indicated that households in the study area are generally suffering from low dietary diversity when compared to that of the FAO's standards.

Households receiving lower income were found to consume more diversified food items than higher-income receivers and this dietary diversity was significantly influenced by many variables. In the paradox, households with better income were found to consume less diversified diet. On the other hand, low-income earning households consume by purchasing food commodities in limited quantity but more diversified items than better income receivers. This has resulted in variation in nutrition security between the rich and poor households.

\subsection{Policy suggestions}

The result of the Gini index indicated high-income inequality among rural households. The variation is mainly attributed to the production potentials of locations and households' socioeconomic situations. This in turn has a high correlation with dietary diversity in a household's meal. To narrow this income variation, farmers have to adopt diversified income options of farm and non-farm activities.

To help rural households, consume more diversified food items and improve their consumption pattern, crop diversification with efficient land-use systems can increase dietary diversity. Moreover, expansion of small-scale irrigation schemes, home gardening, and involving in a variety of livestock production can improve dietary diversity among the rural people. So, working on health extension can change households' consumption behavior and thereby improve the society's wellbeing through the consumption of a balanced diet, which ultimately can reduce the rate of malnourishment, stunting, and chronic lifelong diseases.

Advocating home gardening (vegetables and fruits) through fostering small-scale irrigation diversifies diet. Furthermore, training females can create awareness for family consumption behavior, which ultimately can lead to a well-nourished and healthy family.

\section{Acknowledgments}

We are thankful to Debre Markos University and our colleagues who contributed towards the successful completion of this study. Experts in each district who unreservedly assisted us while gathering data are also acknowledged gratefully.

\section{REFERENCES}

Barrett, C. B. (2002). Food security and food assistance programs. Handbook of agricultural economics, 2, $2103-$ 2190.

Bouis, H. E. (2007). The potential of genetically modified food crops to improve human nutrition in developing countries. The Journal of Development Studies, 43(1), 79-96.

Drewnowski, A., Renderson, S. A., Driscoll, A., \& Rolls, B. J. (1997). The Dietary Variety Score: assessing diet quality in healthy young and older adults. Journal of the American Dietetic Association, 97(3), 266-271.

FAO (Food and Agriculture Organization). (2013) Synthesis of Guiding Principles on Agricultural Programming for Nutrition. Rome, Italy.

Galor, O., \& Moav, O. (2004). From physical to human capital accumulation: Inequality and the process of 
development. The Review of Economic Studies, 71(4), 1001-1026.

Gross, R., Schoeneberger, H., Pfeifer, H., \& Preuss, H. J. (2000). The four dimensions of food and nutrition security: definitions and concepts. SCN News, 20, 20-25.

Israel, G.D. (1992). Determining the sample size. PEOD6, IFAS Extension, University of Florida.

Kennedy, G., Ballard, T., \& Dop, M. C. (2015). Guidelines for measuring household and individual dietary diversity. Nutrition and consumer protection division, food and agriculture organization of the United Nations. 2011.

Linderhof, V. G. M., Powell, J. P., Vignes, R., \& Ruben, R. (2016). The influence of household farming systems on dietary diversity and caloric intake: the case of Uganda.

Quisumbing, A. R., Brown, L. R., Feldstein, H. S., Haddad, L., \& Peña, C. (1996). Women: The key to food security. Food and Nutrition Bulletin, 17(1), 1-2.

Ruel, M. T. (2003). Is dietary diversity an indicator of food security or dietary quality? A review of measurement issues and research needs. Food and Nutrition Bulletin, 24(2), 231-232.

Taruvinga, A., Muchenje, V., \& Mushunje, A. (2013). Determinants of rural household dietary diversity: The case of Amatole and Nyandeni districts, South Africa. Int J Dev Sustainability, 2(4), 2233-2247.

Vakili, M., Abedi, P., Sharifi, M., \& Hosseini, M. (2013). Dietary diversity and its related factors among adolescents: a survey in Ahvaz-Iran. Global journal of health science, 5(2), 181.

World Bank. (2007). Pathways from Agriculture to Nutrition: Pathways, Synergies, and Outcomes. http://siteresources.worldbank.org 